\title{
Farklı Branşlardaki Sporcuların Kollajen Tip V gen (COL5A1) rs12722 \\ Polimorfizmlerinin Dağılımı
}

\author{
Celal BULĞAY*1 ID Canan SERCAN DOĞAN ${ }^{2}$ (D) Gözdem KARAPINAR ${ }^{2}$ iD \\ Tolga POLAT ${ }^{2}$ (i) Ebru ÇETIN ${ }^{1(D)}$ Korkut ULUCAN 2,3 (D)
}

\author{
${ }^{1}$ Gazi Üniversitesi, Spor Bilimleri Fakültesi, ANKARA \\ ${ }^{2}$ Üsküdar Üniversitesi, Tıbbi Genetik ve Moleküler Tanı Laboratuvarı, ISTANBUL \\ ${ }^{3}$ Marmara Üniversitesi, Diş Hekimliği Fakültesi, Tıbbi Biyoloji ve Genetik Bölümü, ÍSTANBUL
}

DOI: $10.31680 /$ gaunjss.793223

Orijinal Makale / Original Article

Geliş Tarihi / Received: 10.09.2020 Kabul Tarihi / Accepted: 25.02.2021 Yayın Tarihi / Published: 22.03.2021

\section{Öz}

Spor yaralanmaları ile ilgili elde edilen bulgular akut ve kronik kas-iskelet sistemi yumuşak doku yaralanmalarının etiyolojisinde genetik faktörlerle ilişkili önemli bir rol oynadığı görülmektedir. Bu çalışmanın amacı, sporcuların branşlarına göre darbeye bağlı olmayan yaralanmalarda etkili olan Kollajen tip $\mathrm{V}$ alfa 1 polimorfizminin (COL5A1) rs12722 genotip ve allel dağılımını analiz etmektir. Yapılan araştırmaya 45 yüzücü, 40 futbolcu, 22 buz hokeyci ve 8 ironman sporcusu olmak üzere toplam 115 katılımcı dahil edildi. Sporcular ulusal ve uluslararası yarışmalara katılan elit seviyedeki yarışmacılardır. Genomik DNA, kullanıcı protokolüne göre Invitrogen DNA İzolasyon Kiti (Invitrogen, ABD) kullanılarak oral epitel hücrelerden izole edildi. Genotipleme işlemi gerçek zamanlı PZR metodu ile gerçekleştirildi. Sporcuların gruplar arası hem genotip hem de allel sıklıklarının karşılaştırılması Chi square/Fisher's exact test analiz yöntemi kullanılmıştır. Gruplar arası genotip ve allel bakımından karşılaştıııldıklarında istatistiksel olarak anlamlı bir farklılık tespit edilmemiştir (sırasıyla $p=0213, p=0.499$ ). Çalışmada tüm branşlarda daha fazla CT genotip ve $\mathrm{C}$ allel taşıyıcıları olduğu saptanmıştır. Ek olarak, ironman sporcularda TT genotip taşıyıcısı olmadığı tespit edilmiştir. Tüm gruplarda rs12722 polimorfizmi için CT genotip ve C allelinin diğer genotiplere göre daha yüksek değerlere sahip olduğu tespit edilmiştir, ancak bu yükseklik istatistiksel açıdan herhangi bir anlamlı bir fark tespit edilmemiştir. Literatür bilgileri de dikkate alındığında bu bağlamda hem sporcular da hem de sedanter bireylerde darbeye bağlı olmayan yaralanma yatkınlığı daha az riskli olduğu düşünülmektedir.

Anahtar Kelimeler: Yaralanma riski, Sporcular, COL5A1, Polimorfizm, Spor Genetiği

\section{Distribution of Collagen Type V gene (COL5A1) rs12722 Polymorphisms of Athletes in Different}

\section{Branches}

\section{Abstract}

Findings related to sports injuries seem to play an important role related to genetic factors in the etiology of acute and chronic musculoskeletal soft tissue injuries. The aim of this study is to analyze the genotype and allele distribution of the Collagen type $V$ alpha 1 gene (COL5A1) rs12722, which is effective in non-impact-related injuries of all branches. A total of 115 participants, including 45 swimmers, 40 footballers, 22 ice hockey players and 8 Ironman athletes, were included in the study. Genomic DNA was isolated from oral epithelial cells using the Invitrogen DNA Isolation Kit (Invitrogen, USA) according to the user protocol. Genotyping was performed by realtime PCR method. No statistically significant difference was found when all groups were compared in terms of genotype and allele ( $p=0213, p=0.499$, respectively). In the study, more CT genotypes and C allele carriers were found in all branches. In addition, it has been determined that there are no TT genotype carriers in ironman athletes. In all groups, CT genotype and C allele were found to have higher values for rs 1800012 polymorphism than other genotypes, but this height did not make any statistically significant difference. Considering the literature information, it is considered that the risk of non-impact injury predisposition is less risky in all braches.

Keywords: Injury risk, Athletes, COL5A1, Polymorphism, Sports genetics

\footnotetext{
${ }^{*}$ Sorumlu Yazar: Korkut ULUCAN
}

e-mail: korkutulucan@hotmail.com 
Bulğay, C., Sercan Doğan, C., Karapınar, G., Polat, T., Çetin, E., ve Ulucan K. (2021). Farklı Branşlardaki Sporcuların Kollajen Tip V gen (COL5A1) rs12722 Polimorfizmlerinin Dağılımı. Gaziantep Üniversitesi Spor Bilimleri Dergisi, 6(1), 63-74.

\section{Giriş}

Spora rekreasyonel, amatör veya profesyonel katılım artıkça yaralanma ve bu yaralanmayı etkileyen faktörlerin önemi de artmaktadır (Gibbon ve ark., 2020; Cerit, Dalip ve Yıldırım, 2020). Spor yaralanmaları, sporcuların performans ve beceri düzeylerini olumsuz etkileyen istenmeyen durumlardır (Özdemir ve ark., 2018). Spor dalı ne olursa olsun, her sporcu spor yaşamı boyunca küçük çaplı ya da ileri düzeyde spor yaralanmasına maruz kalabilmektedir (Karayılan ve ark., 2013). Sporcularda yaralanmalar ve risk faktörlerinin analiz kriterlerini karşılaştıran çalışmalar incelendiğinde, yaralanma etiyolojisinin çok faktörlü olduğu gösterilmiştir (Bulğay ve ark., 2020). Yaş, cinsiyet, bilinçsiz uygulanan antrenman programları, anatomik, hormonal, biyomekanik ve nöromüsküler faktörlerin yanı sıra özelikle son zamanlarda spor bilimleri ve spor hekimliğinin önemli araştırma konusu olan kısmi de olsa sporcuların yaralanma tabanında, genetik faktörlerin etkisi olduğu söylenmektedir (Kumagai ve ark., 2019).

Yapılan araştırmalarda, sporcuların optimal performansa ulaşabilmek veya darbeye bağlı olmayan yaralanmalardan korunmak için çevresel faktörlerin yanı sıra genetik faktörlerden de yararlanması gerektiği bildirilmiştir (Aslan ve ark., 2020; Dinç ve Gökmen, 2019; Eroğlu ve Zileli., 2015). Darbelere bağlı olmayan yaralanma ile ilişkili polimorfizmlerden biri olan kollajen tip $\mathrm{V}$ a1 zincir gen varyantları sadece yaralanmalar değil aynı zamanda kas sertliği ve eklem esnekliğini de etkileyen aday genlerden biri olarak gösterilmiştir (Collins ve Posthumus, 2011). Kollajen tip V a1 geni (COL5A1), tip-V kollejenler 3 alfa1(V) ipliklerinden veya 2 alfa1 (V) ve 1 alfa2 (V) zincirlerinden oluşan trimerik yapılı protein yapılardır. Kollejen yapıları iplik benzeri pro-kollejen zincirlerin bir araya gelmesi ile oluşur, hücrelerarası boşlukta enzimler tarafından modifiye edilerek olgun kollejen yapılarını oluştururlar. Tip-V kollejenler Tip-1 kollejenlerin enine büyümesine destek olur ve Tip $\mathrm{V}$ kollajenin tip I ve tip III kollajenler ile etkileşerek kollajen fibrilogenezinin düzenlenmesinde rol oynar (Suijkerbuijk ve ark., 2019). Tip-V kollajenin alfa1 zinciri COL5A1 geni tarafından sentez edilmektedir. COL5A1 geni, 9q34'da lokalizedir ve aşil tendon yaralanmalarıyla ilişkili olduğu bildirilen ilk kollajen genlerden biri olarak bilinmektedir. COL5A1 geninin 3' translasyona uğramayan bölgesinde (3-UTR), BstUI ve Dpnll olarak adlandırılan 2 farklı polimorfizm gen metabolizması açısından oldukça önemlidir (Mokone ve ark., 2006; Shukla ve ark., 2020). 
Bulğay, C., Sercan Doğan, C., Karapınar, G., Polat, T., Çetin, E., ve Ulucan K. (2021). Farklı Branşlardaki Sporcuların Kollajen Tip V gen (COL5A1) rs12722 Polimorfizmlerinin Dağılımı. Gaziantep Üniversitesi Spor Bilimleri Dergisi, 6(1), 63-74.

Son yıllarda, artan sayıda çalışma tendon ve ligament yaralanmaları gibi kasiskelet sistemi yumuşak doku yaralanmalarına genetik yatkınlıklara dikkat çekmiştir. Örneğin, profesyonel futbolcularda yapılan COL5A1 genindeki varyasyonun ön çapraz bağ (ÖÇB) yırtılması ile ilişkili olduğu bulgulanmıştır. Buna ek olarak aynı çalışmada, CC genotipe sahip bireylerin ÖÇB yırtılmasına karşı koruyucu etki sağlayacağı bildirilmiştir (Lulińska-Kuklik ve ark., 2018). Kafkasya popülasyonunda farklı polimorfizmlerin incelendiği bir meta-analiz çalışmasında, rs12722 polimorfizminin tendon ve ligament yaralanma riskini azaltabileceği belirtilmiştir (Pabalan ve ark., 2018). Yine Kafkas popülasyonunda yapılan başka bir çalışmada rs12722 polimorfizmin tendon ve ligament yaralanma riski ile pozitif ilişkili olduğunu belirtilmiştir. Özelikle TT genotipe sahip bireylerin daha yüksek yaralanma riskine yatkın olduğu tespit edilmiştir (Lv ve ark., 2018). Rs12722 polimorfizmin incelendiği başka bir çalışmada, triatlon ve ultra-maraton yarışmalarına katılan katıımcıların TT genotipinin, kas krampları ile ilişkili olabileceği görülmüştür (O'Connell ve ark., 2013). Ailesel yatkınlık ile ÖÇB yırtığı arasındaki ilişkinin araştıııdığı bir çalışmada ise, cerrahi olarak tanı konulmuş ÖÇB yırtılması hastası ve kontrol grubu incelendi. ÖÇB yırtılmasına sahip kişilerin birinci derecede akrabalarında da ÖÇB yırtılma insidansı, yaralanmamış kişilerin iki katından daha fazla olduğu belirtilmiştir (Flynn ve ark., 2005).

Spor genetiği alanında yapılan araştırmalarda, yaralanma farkındalığı ve önleyici stratejilerdeki bazı ilerlemelere rağmen bu yaralanmaların görülme sıklığının halen yüksek oranda olduğu görülmektedir (De Jonge ve ark., 2011). Bundan dolayı sporcularda darbeye bağlı olmayan yaralanmaların etki mekanizmasını detaylandırmak ve uzun vadeli performans gelişimi için yaralanma risklerini en aza indirgenmek için genotip ve allel bilgilere haiz olmasının önemli olabileceği düşünülmektedir (Bulğay ve ark., 2021). Bu bağlamda, çalışmanın amacı fraklı spor branşlarında ulusal veya uluslararası yarışmalara katılan sporcuların yaralanma etiyolojileri bağlamında COL5A1 rs12722 polimorfizmin genotip ve allel dağılımını belirlemektir.

\section{Yöntem}

\section{Etik Kurul Onayı}

Yapılan araştırma Üsküdar Üniversitesi Etik Kurulu tarafından onaylandı (sayı: B.08.6.YÖK.2ÜS.0.05.0.06/2013/09) ve Helsinki Bildirgesi'ne uygun olarak her 
Bulğay, C., Sercan Doğan, C., Karapınar, G., Polat, T., Çetin, E., ve Ulucan K. (2021). Farklı Branşlardaki Sporcuların Kollajen Tip V gen (COL5A1) rs12722 Polimorfizmlerinin Dağılımı. Gaziantep Üniversitesi Spor Bilimleri Dergisi, 6(1), 63-74.

katılımcıdan çalışma protokolünü ve araştırma çıktılarını açıklayan yazılı bilgilendirilmiş onam alındı.

\section{Katılımcılar}

Yapılan çalışmaya 45 yüzücü, 40 futbolcu, 22 buz hokeyci ve 8 Ironman sporcusu olmak üzere toplam $115 \operatorname{sporcu}\left(\bar{X}_{\text {yaş (yıl) }}=20,49, \quad S s=2,20, \bar{X}_{\text {vücut ağrrlı̆ı }}(\mathrm{kg})\right.$ $\left.=65,12, \mathrm{Ss}=13,50, \bar{X}_{\text {boy uzunluğu }(\mathrm{cm})}=175,79, \mathrm{Ss}=7,50, \overline{\mathrm{X}}_{\text {spor deneyimi (yll) }}=7,04, \mathrm{Ss}=3,24\right)$ gönüllü olarak katılmıştır. Çalışmamıza katılma kriterleri olarak: (1) her sporcu aktif olarak ulusal ya da uluslararası müsabakalara katılıyor olması, (2) herhangi bir kardiyovasküler, bulaşıcı hastalık ve diyabet belirtisinin olmaması, (3) kendisinde, birinci veya ikinci derece akrabalarında herhangi genetik hastalık bulunmaması ve (4) herhangi bir kalıtsal hastalığının bulunmaması.

\section{COL5A1 rs12722 Genotiplemesi}

Genomik DNA, kullanıcı protokolüne göre Invitrogen DNA İzolasyon Kiti (Invitrogen, ABD) kullanılarak oral epitel hücrelerden izole edildi. Her bir numuneden ortalama toplam 20 ng DNA izole edildi ve izolatların saflıkları OD 260/280 spektrofotometrik oranı ile kontrol edildi. COL5A1 rs12722 polimorfizmi tüm numunelerde gerçek zamanlı PCR (RT-PCR) yöntemi (Thermofisher Quantstudio 3, ABD) ve Taqman Genotipleme Kitleri (Katalog no: 4362691 Thermofisher, ABD) kullanılarak genotiplenme işlemleri tamamlandı. Genotipleme işlemleri $10 \mu \mathrm{l}$ reaksiyon hacminde $5 \mu \mathrm{l}$ Genotipleme Master Karışımı (Applied Biosystems, Foster City, CA), 0,5 $\mu$ l genotipleme karışımı (Applied Biosystems), 3,5 $\mu$ l nükleaz-free $\mathrm{H}_{2} \mathrm{O}$ (Thermofisher, ABD) ve $1 \mu$ I DNA içerecek şeklinde gerçekleştirildi. Gerçek zamanlı PCR koşulları kullanıcı protokolüne bağlı olarak tamamlanmıştır.

\section{Verilerin analizi}

Elde edilen verilerin istatistiksel analizleri SPSS 25.0 (Statistical Package for Social Sciences) kullanılarak yapılmıştır. Genetik dağılımın Hardy-Weinberg dengesine uyumu ki-kare testiyle analiz edildi $p>0.05$. Sporcuların gruplar arası hem genotip hem de allel sıklıklarının karşılaştırılması Chi square/Fisher's exact test analiz yöntemi kullanılmıştır. İstatistiksel anlamlılık düzeyi olarak $p<0.05$ kabul edilmiştir. 


\section{Bulgular}

Tablo 1. Branşlara Göre COL5A1 rs12722 Polimorfizm Genotip ve Allel Dağı̆ımları

\begin{tabular}{ccccccc}
\hline COL5A1 rs12722 & \multicolumn{2}{c}{ Genotip Dağılımı } & \multicolumn{2}{c}{ Allel Dağılımı } \\
\hline Grup & $\mathbf{N}$ & CC & CT & TT & C & T \\
\hline Yüzücüler & $45(\% 19)$ & $16(\% 7)$ & $20(\% 8)$ & $9(\% 4)$ & 52 & 38 \\
Futbolcular & $40(\% 17)$ & $8(\% 4)$ & $25(\% 11)$ & $7(\% 3)$ & 41 & 39 \\
Buz Hokeyi & $22(\% 10)$ & $7(\% 3)$ & $8(\% 4)$ & $7(\% 3)$ & 22 & 22 \\
Ironman & $8(\% 4)$ & $3(\% 1)$ & $5(\% 2)$ & --- & 11 & 5 \\
Toplam & 115 & $34(\% 14,8)$ & $58(\% 25,2)$ & $23(\% 10)$ & $126(\% 54,8)$ & $104(\% 45,2)$ \\
\hline
\end{tabular}

Tablo 1'de görüldüğü üzere sporcuların 34'tü CC (\%14,8), 58'i CT $(\% 25,2)$ ve 23'ü de TT (\%10) genotipe sahip oldukları tespit edilmiştir. Allel sayı ve yüzdeleri ise C ve T sırası ile $126(\% 54,8)$ ve $104(\% 45,2)$ olarak belirlenmiştir.

Tablo 2. Branşlara göre COL5A1 rs12722 Polimorfizm Genotip Karşılaştııılması

\begin{tabular}{cccccc}
\hline Grup & $\mathbf{N}$ & $\mathbf{C C}$ & $\mathbf{C T}$ & $\mathbf{T T}$ & $\mathbf{p}$ \\
\hline Yüzücüler & $45(\% 19)$ & $16(\% 7)$ & $20(\% 8)$ & $9(\% 4)$ & \\
Futbolcular & $40(\% 17)$ & $8(\% 4)$ & $25(\% 11)$ & $7(\% 3)$ & .253 \\
Buz hokeyi & $22(\% 10)$ & $7(\% 3)$ & $8(\% 4)$ & $7(\% 3)$ & \\
Ironman & $8(\% 4)$ & $3(\% 1)$ & $5(\% 2)$ & - & \\
\hline
\end{tabular}

$\mathrm{P}<0.5^{*}$

Tablo 2'de görüldüğü üzere sporcuların branşlara göre genotipleri değerlendirildiğinde, yüzücülerde 16'sı CC (\%7), 20'si CT (\%8) ve 9'u TT (\%4) genotipinde oldukları tespit edilmiştir. Futbolcuların genotipleri değerlendirildiğinde 8'i CC (\%4), 25'i CT (\%11) ve 7'si TT (\%3) olarak bulgulanmıştır. Aynı değerlendirmeyi buz hokeyi oynayan sporcularda da yaptığımızda, 7'si CC (\%3), 8'i CT (\%4) ve 7'si TT (\%3) olarak belirlenmiş̧ir. Ironman sporcularda ise 3'ü CC (\%1) ve 5’i CT (\%2), TT genotip taşıyıcısı olmadığı tespit edilmiştir. Branşlar arasında istatistiksel açıdan herhangi bir anlamlı bir farklılık tespit edilmemiştir. $p>0.05$.

Tablo 3. Branşlara Göre COL5A1 rs12722 Polimorfizm Allel Karşılaştırılması

\begin{tabular}{lllll}
\hline Grup & $\mathbf{N}$ & $\mathbf{C}$ & $\mathbf{T}$ & $\mathbf{p}$ \\
\hline Yüzücüler & $45(\% 19)$ & $52(\% 23)$ & $38(\% 17)$ & \\
\hline
\end{tabular}


Bulğay, C., Sercan Doğan, C., Karapınar, G., Polat, T., Çetin, E., ve Ulucan K. (2021). Farklı Branşlardaki Sporcuların Kollajen Tip V gen (COL5A1) rs12722 Polimorfizmlerinin Dağılımı. Gaziantep Üniversitesi Spor Bilimleri Dergisi, 6(1), 63-74.

\begin{tabular}{lllll}
\hline Futbolcular & $40(\% 17)$ & $41(\% 18)$ & $39(\% 17)$ & .499 \\
Buz hokeyi & $22(\% 10)$ & $22(\% 10)$ & $22(\% 10)$ & \\
Ironman & $8(\% 4)$ & $11(\% 5)$ & $5(\% 2)$ & \\
\hline
\end{tabular}

$\mathrm{P}<0.5^{*}$

Tablo 3'te görüldüğü üzere sporcuların branşlara göre allel karşılaştırılması değerlendirildiğinde, yüzücülerde C ve T alleleri için sırasıyla 52 (\%23) ve 38 (\%17) olarak tespit edilmiştir. Futbolcuların Allel ve sayı yüzdeleri ise $C$ ve $T$ alleleri için sırasıyla 41 (\%18) ve 39 (\%17) olarak saptanmıştır. Aynı değerlendirmeyi buz hokeyi oynayan sporcularda da yaptığımızda, C ve T alleleri için sırasıyla 22 (\%10) ve 22 (\%10) olarak saptanmıştır. Ironman sporcularda Allel ve sayı yüzdeleri ise C ve T alleleri için sırasıyla $11(\% 5)$ ve 5 (\%2) olarak saptanmıştır. Tablo 3’te görüldüğü üzere branşlar arasında istatistiksel açıdan herhangi bir anlamlı bir fark tespit edilmemiştir ( $p>0.05)$.

\section{Tartışma ve Sonuç}

Son yirmi yılda yapılan genetik araştırmalar, sportif performansta önemli rol alan genetik faktörlerin yanı sıra (Cupeiro ve ark., 2010; Ulucan, 2016; Wang ve ark., 2016) spor yaralanmaları riskinin artmasıyla ilişkilendirilecek spesifik belirleyicileri özetlemektedir (Collins ve ark., 2015; Rahim ve ark., 2016). Bu genetik bilgilerin kullanılması, darbeye bağlı olmayan yaralanmalar ile ilişkilendirilebilecek polimorfizmleri belirlemek, sporcular için bireysel antrenman yöntemlerinin oluşturulmasında ve yaralanmaların engellenmesinde önemli bir rol oynayabilir. Ayrıca yaralanma riski yüksek genotipli bireylerin belirlenmesi ile ya bireye özgü antrenman programları oluşturulmasına ya da kendileri için ağır sayılabilecek antrenmanlara adapte olabilmesi farklı yaklaşım ve stratejileri geliştirebilecektir (Cięszczyk ve ark., 2017; Eken ve ark., 2018).

Bu bağlamda araştırma, Türkiye'de farklı kulüplere bağlı farklı branşlarda (yüzme, futbol, buz hokeyi ve ıronman) lisanslı olarak ulusal veya uluslararası düzeyde müsabakalara katılan sporcuların yaralanma etiyolojileri bağlamında COL5A1 rs12722 polimorfizm genotip ve allel dağılımları değerlendirilmiştir. Yaralanma ve COL5A1 arasındaki ilişkinin daha açık şekilde yansıtılması amacıyla ise gruplar arası karşılaştırmalar yapılmıştır. Tüm grupların genotip ve allel bakımından karşılaştırılmasında gruplar arasında anlamlı herhangi bir farklılık tespit edilmemiştir. Bunun yanında genotip ve allel dağılımları incelendiğinde anlamlı bir farklılık olmamakla birlikte tüm branşlarda daha fazla CT genotip ve C allel taşıyıcıları 
Bulğay, C., Sercan Doğan, C., Karapınar, G., Polat, T., Çetin, E., ve Ulucan K. (2021). Farklı Branşlardaki Sporcuların Kollajen Tip V gen (COL5A1) rs12722 Polimorfizmlerinin Dağılımı. Gaziantep Üniversitesi Spor Bilimleri Dergisi, 6(1), 63-74.

olduğu saptanmıştır. Ek olarak, ıronman sporcularda TT genotip taşıyıcısı olmadığı tespit edilmiştir.

COL5A1 rs12722 (C-T) polimorfizminin üzerinde yapılan çalışmalarda, ÖÇB yaralanmasından muzdarip olan ve olmayan bireylerde rs12722 (C-T) polimorfizmi incelendiğinde, allel kıyaslamalarında $T$ allel sıklığının hastalarda kontrol grubuna göre anlamlılık göstermesine karşın, C allel sıklığı kontrol grubunda hasta grubuna göre daha yüksek olduğu belirtilmiştir. Araştırıcılar, T alleli için ÖÇB yaralanmasında bir risk faktörü olarak belirlenirken, $C$ allel taşıyıcılarının ÖÇB yaralanmasına karşı koruyucu bir etkiye sahip olduğu gösterilmiştir (Can, 2020). Benzer bir başka çalışmada, cerrahi olarak teşhis edilen ÖÇB yırtılması olan erkek profesyonel futbolcular ile ligament ve/veya tendon yaralanma öyküsü olmayan sağlıklı erkek profesyonel futbolcu üzerinde yapılan çalışmada ise, rs12722 polimorfizmin ÖÇB yırtılması ile ilişkili olduğu, CC genotip taşıyıcıların ÖÇB yırtılmasında koruyucu bir etkisi olduğu gösterilmiştir (Lulińska-Kuklik ve ark., 2018). Yine rs12722 polimorfizmin incelendiğinde çalışmalarda, TT genotipe sahip bireylerin darbeye bağlı olmayan yaralanmalara daha yatkın olduğu tespit edilmiştir (O'Connell ve ark., 2013; Wenstrup ve ark., 2006). Mokone ve ark., (2006) de C alleli taşıyan bireylerde tendon patalojisi semptomlarının gelişme olasıığının daha az olduğu görülmüştür (Mokone ve ark., 2006). İlgili literatür incelendiğinde, C allel taşıyıcıların yaralanma üzerinde koruyucu bir etkiye sahip olduğunu göstermiştir. Ve bunun yanında TT genotip veya $\mathrm{T}$ allelinin hasta bireylerde daha fazla taşınması, bunların yaralanma risk faktörü olduğunu düşündürmektedir. Yapılan çalışmada da $C$ allel ve CC veya $C T$ genotip taşıyıcıların daha fazla bulunması literatür ile tutarlı olduğu ve tüm branşlarda darbeye bağıı olmayan yaralanmalarda az riskli olduğunu söylenebilir.

Ayrıca, COL5A1 genindeki mutasyonun, tip $\mathrm{V}$ kollajenin \%50 azalmasıyla sonuçlandığı, ayrıca zayıf organize fibrillere, gerilme kuvvetinin ve bağ doku sertliğinin azalmasına neden olduğu gösterilmiştir (Wenstrup ve ark., 2006). Ek olarak, rs12722 polimorfizmi hem bilateral kuadriseps tendon yırtılması ile ilişkilendirilmiştir (Longo ve ark., 2010). Hem de tenisçi dirseği için genetik risk faktörü olarak tanımlanmıştır (Altinisik ve ark., 2015). Rs12722-BstUI polimorfizmin kronik aşil tendon ile ilişkili olduğu, özelikle CC genotip taşıyıcıların tendinopatili bireylerde daha az olduğunu belirtmişleridir (September ve ark., 2009). İronman (yüzme, koşu, bisiklet) sporcularda yapılan bir çalışmada ise, COL5A1BstUI TT genotip taşıyıcı sporcularda dayanıklılık performansının diğer genotip taşıyıcılara göre daha yüksek 
Bulğay, C., Sercan Doğan, C., Karapınar, G., Polat, T., Çetin, E., ve Ulucan K. (2021). Farklı Branşlardaki Sporcuların Kollajen Tip V gen (COL5A1) rs12722 Polimorfizmlerinin Dağılımı. Gaziantep Üniversitesi Spor Bilimleri Dergisi, 6(1), 63-74.

olduğu bildirilmiştir (Posthumus ve ark., 2011). Yapılan çalışmada elde edilen bulguların literatür ile benzer bulgulara sahip olması araştırmayı destekler nitelikte olduğu, özelikle ironman sporcularda TT genotip taşıyıcı olmaması tüm branşlara göre daha az yaralanma risk faktörü olduğu düşünülmektedir. Kadın balerinler ile yapılan bir çalışmada, COL5A1 polimorfizminin esneklik ve yaralanma riski ile ilişkisi olmadığı saptanmıştır (Kim ve ark., 2014). Yapılan çalışmada kadın veya erkek olarak belirlenmediğinden cinsiyete özgü bu ilişkinin nedenini bilinmemektedir. Cinsiyet değişkenin yanı sıra performans açısından da değerlendirilmediğinden bu konuda yorum yapabilmemizi kısıtlamış bulunmaktadır.

Sonuç olarak, yapılan çalışmadan elde edilen bulgular ve literatür incelemesi sonucunda, $T$ allel taşıyıcıların yaralanma risk faktörlerden biri olabileceğini ve $C$ allel taşıyıcıların darbelere bağlı olmayan yaralanmalarda koruyucu bir etkiye sahip olduğunu söylenebilir. Ek olarak TT genotip taşıyıcıların tendon sertliğine neden olduğu bunun sonucunda yıpranmalara ve kopmalara olan riski artırmakla ilişkili olduğu düşünülmektedir. COL5A1 rs12722 polimorfizminin darbeye bağlı olmayan yaralanmalar ile ilişkili olup olmadığına daha sağlıkı bilgi verebilmek için geniş örnek gruplu ile boylamsal çalışmalara intiyaç duyulmaktadır. Özetle, gerek kasların çalışmasına etki eden yapısal molekülleri kodlayan genlerin analizleri, gerekse oluşan kas yaralarının onarılmasında rol alan molekülleri sentezleyen genlerin analizi yaralanma yatkınlarının belirlenmesinde ve sporcuların daha yüksek performans göstermeleri konusunda spor bilimcileri, antrenörler ve spor hekimlerine önemli bilgiler sağlayacağını söylenebilir.

\section{Kaynaklar}

Altinisik, J., Meric, G., Erduran, M., Ates, O., Ulusal, A. E., \& Akseki, D. (2015). The BstUI and Dpnll variants of the COL5A1 gene are associated with tennis elbow. American Journal of Sports Medicine, 43(7), 1784-1789.

Aslan, B. T., Eken, B. F., Kaman, T., Sercan, C., \& Ulucan, K. (2020). Collagen type I alpha 1 (COL1A1) rs1800012 polymorphism in cyclists Study subjects. 11(2), $1-4$.

Bulğay, C., Orhan, Ö., \& Çetin, E. (2020). Uzun Mesafe Koşucularında Alt Ekstremite Yaralanmaları ve Risk Faktörleri. Türkiye Klinikleri Spor Bilimleri Dergisi.

Bulgay C, Dogan CS, Cetin E, Polat T, Eken BF, Akkoc O, et al. (2021). Collagen type 1 gene (COL1A1) rs1800012 polymorphism in long and short distance 
runners. Turk J Sports Med. 56(1), 28-32.

Can, O. (2020). Ön çapraz bağ rüptürünün moleküler ve anatomopatolojik temelinin araştırıması, uzmanlık tezi, Ortopedi ve Travmatoloji Anabilim Dalı, Sivas Cumhuriyet Üniversitesi.

Cerit, M., Dalip, M., \& Yildirim, D. S. (2020). Genetıcs And Athletıc Performance. Research in Physical Education, Sport and Health, 9(2), 65-76 https://doi.org/10.46733/PESH20920065c

Cięszczyk, P., Willard, K., Gronek, P., Zmijewski, P., Trybek, G., Gronek, J., WeberRajek, M., Stastny, P., Petr, M., Lulińska-Kuklik, E., Ficek, K., KemeryteRiaubiene, E., Maculewicz, E., \& September, A. V. (2017). Are genes encoding proteoglycans really associated with the risk of anterior cruciate ligament rupture? Biology of Sport. 34(2), 97-103.

Collins, M., \& Posthumus, M. (2011). Type V collagen genotype and exercise-related phenotype relationships: A novel hypothesis. Exercise and Sport Sciences Reviews, 39(4), 191-198.

Collins, M., September, A. V., \& Posthumus, M. (2015). Biological variation in musculoskeletal injuries: Current knowledge, future research and practical implications. British Journal of Sports Medicine, 49(23), 1497-1503.

Cupeiro, R., Benito, P. J., Maffulli, N., Calderón, F. J., \& González-Lamuño, D. (2010). MCT1 genetic polymorphism influence in high intensity circuit training: A pilot study. Journal of Science and Medicine in Sport, 13(5), 526-530.

De Jonge, S., Van Den Berg, C., De Vos, R. J., Van Der Heide, H. J. L., Weir, A., Verhaar, J. A. N., Bierma-Zeinstra, S. M. A., \& Tol, J. L. (2011). Incidence of midportion Achilles tendinopathy in the general population. British Journal of Sports Medicine, 45(13), 1026-1028.

Dinç, N. ve Gökmen, M. H. (2019). Atletik Performans ve Spor Genetiği. Celal Bayar Üniversitesi Sağık Bilimleri Enstitüsü Dergisi, 6(2), 127-137. DOI: 10.34087/cbusbed.529159

Eken, B. F., Sercan, C., Kaya, D., \& Ulucan, K. (2018). Darbeye Bağlı Olmayan Yumuşak Doku Yaralanmalarında Moleküler Yaklaşım Molecular Approach to Soft Tissue Injuries Not Affected by Pulse. Avrasya Spor Bilimleri Araştırmaları •, $3(1), 15-25$.

Eroğlu, O., \& Zileli, R. (2015). The effect of genetic factors on sportive 
Bulğay, C., Sercan Doğan, C., Karapınar, G., Polat, T., Çetin, E., ve Ulucan K. (2021). Farklı Branşlardaki Sporcuların Kollajen Tip V gen (COL5A1) rs12722 Polimorfizmlerinin Dağılımı. Gaziantep Üniversitesi Spor Bilimleri Dergisi, 6(1), 63-74.

performance. Uluslararası Spor, Egzersiz \& Antrenman Bilimi Dergisi, 1(1), 6376. $h$ ttps://doi.org/10.18826/ijsets.65225

Flynn, R. K., Pedersen, C. L., Birmingham, T. B., Kirkley, A., Jackowski, D., \& Fowler, P. J. (2005). The familial predisposition toward tearing the anterior cruciate ligament: A case control study. American Journal of Sports Medicine, 33(1), 2328.

Gibbon, A., Raleigh, S. M., Ribbans, W. J., Posthumus, M., Collins, M., \& September, A. V. (2020). Functional COL1A1 variants are associated with the risk of acute musculoskeletal soft tissue injuries. Journal of Orthopaedic Research, Jan., 1-9. Karayılan, Ş., Dönmez, G., Babayeva, N., Yargıç, P., Korkusuz, F., \& Doral, N. (2013). Spor Yaralanmaları ve Genetik. 48(4), 139-146.

Kim, J. H., Jung, E. S., Kim, C.-H., Youn, H., \& Kim, H. R. (2014). Genetic associations of body composition, flexibility and injury risk with ACE, ACTN3 and COL5A1 polymorphisms in Korean ballerinas. Journal of Exercise Nutrition and Biochemistry, 18(2), 205-214.

Kumagai, H., Miyamoto-Mikami, E., Hirata, K., Kikuchi, N., Kamiya, N., Hoshikawa, S., Zempo, H., Naito, H., Miyamoto, N., \& Fuku, N. (2019). ESR1 rs2234693 Polymorphism Is Associated with Muscle Injury and Muscle Stiffness. Medicine and Science in Sports and Exercise, 51(1), 19-26.

Longo, U. G., Fazio, V., Poeta, M. L., Rabitti, C., Franceschi, F., Maffulli, N., \& Denaro, V. (2010). Bilateral consecutive rupture of the quadriceps tendon in a man with BstUI polymorphism of the COL5A1 gene. Knee Surgery, Sports Traumatology, Arthroscopy, 18(4), 514-518.

Lulińska-Kuklik, E., Rahim, M., Domańska-Senderowska, D., Ficek, K., MichałowskaSawczyn, M., Moska, W., Kaczmarczyk, M., Brzeziański, M., BrzeziańskaLasota, E., Cięszczyk, P., \& September, A. V. (2018). Interactions between COL5A1 Gene and Risk of the Anterior Cruciate Ligament Rupture. Journal of Human Kinetics, 62(1), 65-71.

Lv, Z. T., Gao, S. T., Cheng, P., Liang, S., Yu, S. Y., Yang, Q., \& Chen, A. M. (2018). Association between polymorphism rs12722 in COL5A1 and musculoskeletal soft tissue injuries: A systematic review and meta-analysis. Oncotarget, 9(20), 15365-15374.

Mokone, G. G., Schwellnus, M. P., Noakes, T. D., \& Collins, M. (2006). The COL5A1 gene and Achilles tendon pathology. Scandinavian Journal of Medicine and 
Science in Sports, 16(1), 19-26.

O'Connell, K., Posthumus, M., Schwellnus, M. P., \& Collins, M. (2013). Collagen genes and exercise-associated muscle cramping. Clinical Journal of Sport Medicine, 23(1), 64-69.

Özdemir, M., Tanır, H., Ilkım, M., \& Şeker, T. (2018). Sports injuries in 15-17 year-old male athlete students participating on school teams. Turkish Journal of Sport and Exercise, 20(2), 44-48.

Pabalan, N., Tharabenjasin, P., Phababpha, S., \& Jarjanazi, H. (2018). Association of COL5A1 gene polymorphisms and risk of tendon-ligament injuries among Caucasians: a meta-analysis. Sports Medicine - Open, 4(1).

Posthumus, M., Schwellnus, M. P., \& Collins, M. (2011). The COL5A1 gene: A novel marker of endurance running performance. Medicine and Science in Sports and Exercise, 43(4), 584-589.

Rahim, M., Collins, M., \& September, A. (2016). Genes and Musculoskeletal SoftTissue Injuries. Içinde Medicine and Sport Science (C. 61, ss. 68-91). S. Karger AG.

September, A. V., Cook, J., Handley, C. J., Van Der Merwe, L., Schwellnus, M. P., \& Collins, M. (2009). Variants within the COL5A1 gene are associated with Achilles tendinopathy in two populations. British Journal of Sports Medicine, 43(5), 357365.

Shukla, M., Gupta, R., Pandey, V., Tiwari, P. K., \& Amrathlal, R. S. (2020). COLIA1 + 1245 G > T Sp1 Binding Site Polymorphism is Not Associated with ACL Injury Risks Among Indian Athletes. Indian Journal of Orthopaedics, 1(0123456789).

Suijkerbuijk, M. A. M., Ponzetti, M., Rahim, M., Posthumus, M., Häger, C. K., Stattin, E., Nilsson, K. G., Teti, A., Meuffels, D. E., van der Eerden, B. J. C., Collins, M., \& September, A. V. (2019). Functional polymorphisms within the inflammatory pathway regulate expression of extracellular matrix components in a genetic risk dependent model for anterior cruciate ligament injuries. Journal of Science and Medicine in Sport, 22(11), 1219-1225.

Ulucan, K. (2016). Literature Review of Turkish Sportsmen in Terms of ACTN3 R577X Polymorphism. Clinical and Experimental Health Sciences, 6(1), 44-47.

Wang, G., Tanaka, M., Eynon, N., North, K. N., Williams, A. G., Collins, M., Moran, C. N., Britton, S. L., Fuku, N., Ashley, E. A., Klissouras, V., Lucia, A., Ahmetov, I. I., De Geus, E., Alsayrafi, M., \& Pitsiladis, Y. P. (2016). The Future of Genomic 
Bulğay, C., Sercan Doğan, C., Karapınar, G., Polat, T., Çetin, E., ve Ulucan K. (2021). Farklı Branşlardaki Sporcuların Kollajen Tip V gen (COL5A1) rs12722 Polimorfizmlerinin Dağılımı. Gaziantep Üniversitesi Spor Bilimleri Dergisi, 6(1), 63-74.

Research in Athletic Performance and Adaptation to Training. Medicine and Sport Science, 61(October), 55-67.

Wenstrup, R. J., Florer, J. B., Davidson, J. M., Phillips, C. L., Pfeiffer, B. J., Menezes, D. W., Chervoneva, I., \& Birk, D. E. (2006). Murine model of the Ehlers-Danlos syndrome: col5a1 haploinsufficiency disrupts collagen fibril assembly at multiple stages. Journal of Biological Chemistry, 281(18), 12888-12895. 